\title{
Effects of Covid-19 pandemic in Turkey: Physical activity, smartphone usage, musculoskeletal system
}

\author{
Sinem SUNER KEKLIK ${ }^{1, *}$ i], Ayse NUMANOGLU AKBAS ${ }^{1}$ [i]
}

${ }^{1}$ Department of Physiotherapy and Rehabilitation, Faculty of Health Sciences, Sivas Cumhuriyet University, Sivas, Turkey

\begin{abstract}
\begin{tabular}{ccccc}
\hline Received: 05.04 .2021 & $\bullet$ & Accepted/Published Online: 23.04 .2021 & $\bullet$ & Final Version: 30.08 .2021 \\
\hline
\end{tabular}
\section{Abstract}

This study aims to evaluate relationship between physical activity level, smartphone usage, back and neck health during Covid-19 pandemic. Participants between ages of 18-65 were included in study. Smartphone usage was evaluated with Smartphone Addiction Scale-Short Version, physical activity levels with short form of International Physical Activity Questionnaire. Oswestry Disability Index and Neck Bournemouth Questionnaire was used to evaluate back and neck problems. A total of 251 people (179 women, 72 men, age: 28.11 \pm 9.49 years, min-max: 18-62 years) participated in study. 134 participants (53.38\%) had low physical activity levels; 35 individuals (13.94\%) had sufficient physical activity levels while 82 participants $(32.66 \%)$ were not physically active. A weak positive correlation was found between neck pain and total score of smartphone addiction scale, daily smartphone usage time, daily smartphone check frequency, and first check time after waking up ( $\mathrm{r}=0.199$, $\mathrm{r}=0.149, \mathrm{r}=0.132$, respectively). A weak negative correlation was found between neck pain and first check time after waking up ( $\mathrm{r}=-0.145)$. As a result of study, it was observed that physical activity levels were insufficient in majority of individuals who participated in survey. The relationships we expected between physical activity level, smartphone usage characteristics, low back and neck health could not be demonstrated, only weak relationships were found between some features of smartphone use and neck health. We believe that finding solutions to increase physical activity levels of individuals during pandemic period will have both protective effects on health and will prevent problems by affecting musculoskeletal system positively.
\end{abstract}

Keywords: Covid-19, musculoskeletal system, smartphone

\section{Introduction}

The new coronavirus (Severe Acute Respiratory Syndromecoronavirus-2 (SARS-CoV-2)), which was first reported in November 2019 and affected the whole world in a short time, caused a global health hazard and has been declared as a pandemic by the World Health Organization (WHO) (1). In countries with the Covid-19 pandemic, strict measures had to be taken to slow down the spread of transmission and thus prevent the health system from collapsing (2). Precautions such as preferring to work from home, closing schools, limiting shops, restaurants and business areas/services considered not in urgent need have been implemented and thus tried to ensure compliance with the rules of social distancing (2, 3). However, these measures have caused disruption of daily routines (3). There are significant concerns about how these changes in normal daily activities will affect public health and welfare (1).

As a result of home quarantine during the pandemic, physical activity and exercise levels of individuals have significantly decreased (2). Yet, physical activity is necessary for a healthy life. Being physically active is essential for the protection and improvement of musculoskeletal health, also.
The time spent on smartphones has also increased with the increase in free time at home during the pandemic period (8). In order to manage the anxiety caused by Covid-19, and the associated social isolation, many people may turn to excessive phone use, especially in the presence of home quarantine and in the absence of numerous other activities (8). Increased use of smartphones can also lead to prolonged stay in inappropriate postures and static positions, resulting in disrupting the biomechanics of the spine, causing pain, especially in the spine (9). It is stated in the literature that the first affected area is the neck due to the inappropriate posture taken while using smartphone (10).

Even before the Covid-19 pandemic, inadequate participation in physical activity has already been identified as a global public health problem, with more than a quarter of all adults have been reported that they do not reach the levels of physical activity required to maintain health (11). The sedentary lifestyle trend caused by the changes in lifestyle and technology taking an enormous place in our lives in recent years, has become more pronounced with the pandemic period. The sedentary lifestyle attitude a risk in terms of chronic health problems, mortality and morbidity as opposed 
to being physically active (12).

It is not known how long the Covid-19 pandemic will last and when societies can return to their normal lifestyle habits (13). Considering the harmful effects of physical inactivity as well as the treatment of people diagnosed with Covid-19, a second priority is the protection of health among people who have not been diagnosed with Covid-19 (3). Social distance and "staying at home" easily limit person-to-person transmission, but long-term physical inactivity as a result of quarantine procedures causes loss of condition that can easily impair overall health and well-being (3).

For this reason, it is necessary to determine how much the process caused by the pandemic affects the physical activity levels of individuals, how much it increases the dependence on technology, and how much the low back and neck health is affected in relation to these negative situations. For this reason, the aim of our study is to measure the relationship between physical activity level, smartphone addiction, and low back and neck health in individuals aged 18-65 during the Covid-19 pandemic.

\section{Materials and methods}

Participants between the ages of 18-65 who agreed to participate in the study were included in the study. Those with orthopaedic or neurological problems that prevent physical activity, congenital musculoskeletal deformities, uncontrollable chronic diseases, cognitive problems that prevent communication, and those who do not use mobile phones were excluded from the study. In addition, those who underwent Covid-19 were also excluded from the study so that the musculoskeletal system pain that can be seen due to Covid-19 disease does not affect the evaluation the parameters of our study.

The study initiated upon the permission of the Ethics Committee of the non-invasive Clinical Trials of Sivas Cumhuriyet University (Decision number: 2020-07/07, Date: 08.07.2020). The participants were informed about the purpose and content of the study and their informed consents were obtained online. In addition, necessary permits for the study were obtained from the Ministry of Health. The assessments were made through online forms since the faceto-face meeting may attitude a risk due to the pandemic. The first part of the form included information about age, gender, height, weight, marital status, body mass index, mobile phone/smartphone usage status, musculoskeletal system, and cardiovascular problems of the participants. Turkish translation of the 10-question Short Form of Smartphone Addiction Scale (SAS-SV) was used for the evaluation of smartphone addiction (14-16). The questionnaire questions were evaluated with six-point Likert scale. Scale scores vary between 10-60, while high scores indicate an increased risk of addiction. In the Korean sample, the cut-off score was determined as 31 for men and 33 for women. The Cronbach alpha coefficient of the original form's internal consistency and concurrent validity was 0.91 (15). The reliability of the Turkish form of SAS-SV was performed by Noyan et al (14).

The physical activity levels of participants were evaluated by the Turkish translation of the International Physical Activity Questionnaire-Short Form (IPAQ-SF) consisting of 7 questions $(17,18)$. In the short form, there are seven questions during the last 7 days about the time spent in walking, moderate and vigorous activities, and the frequency of activities. The time spent sitting was considered as a separate question. The times spent are multiplied by the metabolic equivalents (MET) present at the per activity scale and the average of the results for all materials gives the overall physical activity score. Physical activity levels are classified as physically inactive $(<600 \mathrm{MET}-\mathrm{min} /$ week), low physical activity level (600-3000 MET-min/week), sufficient physical activity level (>3000 MET-min/week) (17).

The Turkish version of the Oswestry Disability Index (ODI) was used to determine back problems $(19,20)$. This scale includes 10 questions that examine the level of pain and the change in pain level and the differences in daily life activities due to pain. There are 6 options in each question with scores varying between 0 and 5, respectively. Participants were asked to mark the option they find closest to them as an answer to each question. The result value of the survey was obtained by summing the scores of the options they marked. The maximum score to be taken from this scale is 50 points. Option scores are 1 is 0 points, 2 is 1 point, 3 is 2 points, 4 is 3 points, 5 is 4 points, and 6 is 5 points. The evaluation is done as follows;

0 points: No functional impairment

1-10 points: Mild functional impairment

11-30 points: Moderate functional impairment

31-50 points: Severe functional impairment (20).

The Turkish version of the Neck Bournemouth Questionnaire was used to evaluate neck problems. It revised from Bournemouth Low Back Pain Questionnaire in 2002 by Bolton et al (21). The Neck Bournemouth Questionnaire is a survey in which pain intensity, daily social-functional level, anxiety, depression level, cognitive and behavioral aspects of fear-avoidance belief, and ability to cope with the pain are questioned. The Neck Bournemouth Questionnaire consists of seven questions and the answers are scored on a digital analog scale ranging from 0 to 10 . The maximum score that can be obtained from the survey is 70 , and a high score indicates a high disability (21).

\subsection{Statistical analysis}

The data obtained from our study were evaluated with the Windows-based SPSS analysis software (Version 22, Armonk, NY: IBM Corporation). The normality of the data was evaluated with Kolmogorov-Smirnov Test. Spearman Rank Correlation Coefficient was used to determine the relationship between physical activity levels, smartphone addiction, and low back and neck health, and Chi-square test 


\section{Suner Keklik and Numanoglu Akbas / J Exp Clin Med}

was used to evaluate the data obtained by counting.

\section{Results}

179 women $(71.31 \%), 72$ men $(28.68 \%)$, totally 251 people (age: $28.11 \pm 9.49$ years, min-max: $18-62$ years) participated in the study. The sociodemographic characteristics of the participants were shown in Table 1 . Of the 251 individuals participating in the study, 178 (70.91\%) stated that they or the people around them did not have Covid-19 infection. 69 people $(27.49 \%)$ stated that they had family or friends' group who infected with Covid-19 and did not live in the same house, while 4 people (1.58\%) stated that people living in the same house $(0.39 \%)$ were infected. Physical activity levels of the individuals are given in Table 1. While 82 of the participants $(32.66 \%)$ were not physically active, 134 individuals (53.38\%) had low physical activity level, and only 35 individuals (13.94\%) had sufficient physical activity level.

Table 1. Sociodemographic characteristics of the participants and study variables

Frequency Percentage

\begin{tabular}{|c|c|c|c|}
\hline Gender & Female & 179 & 71.31 \\
\hline Marital & Male & 72 & 28.68 \\
\hline Status & Single & 163 & 64.94 \\
& Married & 88 & 35.05 \\
\hline & Primary/ & 4 & 1.59 \\
\hline Education & Secondary & 3 & 1.19 \\
\hline level & High School Graduate & 101 & 40.23 \\
\hline & Some Collage Graduate & 14 & 5.57 \\
\hline Working & Bachelor & 98 & 39.04 \\
\hline Status & Postgraduate education & 31 & 12.35 \\
\hline Smoking & Master / Doctorate) & 106 & 42.23 \\
\hline Habit & Working & 145 & 57.76 \\
\hline & Not Working & 47 & 18.72 \\
\hline Physical & Yot physically active & 82 & 32.66 \\
\hline Activity & Low physical activity & 134 & 53.38 \\
\hline Level & Adequate physical activity & 35 & 13.94 \\
\hline
\end{tabular}

There was no correlation between the duration and frequency of smartphone use, and the time passed from waking up to using the smartphone, and the back, neck, and leg pain of the individuals participating in the study $(\mathrm{p}>0.05)$ (Table 2). When the relationship between neck pain scores and smartphone usage and physical activity levels was examined, a weak positive correlation was found between neck pain and smartphone addiction scale total score, daily smartphone usage time, and daily smartphone check frequency $(\mathrm{r}=0.199, \mathrm{r}=0.149, \mathrm{r}=0.132$, respectively). A weak negative correlation was found between neck pain and the first check time after waking up $(r=-0.145)$. There was no relationship between back pain and smartphone usage and physical activity levels ( $>00.05)$ (Table 3$)$.

\section{Discussion}

As a result of the study, it was observed that the physical activity levels were insufficient for the majority of individuals (13.94\%) who participated in the study. However, despite insufficient physical activity levels, no relationship was found between physical activity level and low back and neck problems. In other words, it has not been shown that people with insufficient or low physical activity level have more low back and/or neck problems. Similarly, no relationship was found between smartphone usage characteristics and waist, neck and leg pain. Only weak correlations were found between smartphone addiction and some features of smartphone use and neck survey results.

The disease caused by the Covid-19 virus, which has been in our lives since November 2019 (1) is expected to reduce the participation in physical activity and cause adverse effects on the general health of the population with the measures taken in countries where the pandemic is seen (2).

Physical activity is essential for a healthy life and being physically active is important for maintaining and improving musculoskeletal health (4-7). Physical inactivity is one of the most important risk factors for major disease morbidity (22). This applies not only to the general population but also to older adults and chronically ill populations, particularly those at high risk of death from Covid-19 (23). Our bodies require a relatively long period of time to take advantage of the healthy adaptations produced by physical activity (24-26). However, it takes only a few days to reverse these positive adaptations and the body returns to a physiological state similar to the initial condition or worse (27). This means that trying to lead an active lifestyle during home quarantine is necessary to avoid negative consequences (2). Despite all these beneficial effects, it was found that approximately $86.2 \%$ of the individuals participating in our study were not physically active or had a low level of physical activity. Even before the Covid-19 pandemic, inadequate physical activity was considered a public health threat (11). As a result of the measures taken with the pandemic period, physical activity and exercise levels have decreased significantly (2). For this reason, the results obtained from the study reflect the expected outcome. Regulations to protect against Covid-19 and keep people safe can cause a decrease in physical activity and an increase in sedentary behavior, which can lead to worsening of chronic health conditions and increased risks.

Today, the use of smartphones has increased with the area covered by technology in our lives (9). It is stated in the literature that long-term smartphone use is associated with mental health symptoms and many people seek to eliminate negative emotions, and emotional relief through easily accessible smartphones and devices that can be connected to the internet, but it is emphasized that such coping approaches may lead to negative consequences (8). Covid-19 pandemic (28) and the related home quarantine and social distance caused anxiety and negative emotions that increased greatly in society $(29,30)$. Given that social isolation causes 


\section{Suner Keklik and Numanoglu Akbas / J Exp Clin Med}

emotional distress and negative impact, anxiety specific to Covid-19 as well as general anxiety and depression can increase smartphone use (8). A study conducted in China revealed that there is a strong relationship between phone usage times and both general anxiety and anxiety specific to

Table 2. Comparison of smartphone usage characteristics of individuals with and without back, neck and leg pain

\begin{tabular}{|c|c|c|c|c|c|c|c|}
\hline & & & $\begin{array}{l}\text { No low back, } \\
\text { neck, leg pain }\end{array}$ & $\begin{array}{l}\text { With back } \\
\text { and leg pain }\end{array}$ & $\begin{array}{l}\text { With neck } \\
\text { pain }\end{array}$ & $\begin{array}{l}\text { Both with a } \\
\text { back-leg and } \\
\text { neck pain }\end{array}$ & $\mathrm{p}$ \\
\hline \multirow{10}{*}{$\begin{array}{l}\text { Smartphone usage } \\
\text { (hours / day) }\end{array}$} & \multirow{2}{*}{$\begin{array}{l}\text { Less than } 2 \\
\text { hours }\end{array}$} & Number & 35 & 18 & 9 & 21 & \multirow{10}{*}{0.465} \\
\hline & & Percent \% & 42.2 & 21.7 & 10.8 & 25.3 & \\
\hline & \multirow{2}{*}{ 3-4 hours } & Number & 29 & 21 & 16 & 19 & \\
\hline & & Percent \% & 34.1 & 24.7 & 18.8 & 22.4 & \\
\hline & \multirow{2}{*}{ 5-6 hours } & Number & 14 & 9 & 12 & 16 & \\
\hline & & Percent \% & 27.5 & 17.6 & 23.5 & 31.4 & \\
\hline & \multirow{2}{*}{$\begin{array}{l}\text { More than } 6 \\
\text { hours }\end{array}$} & Number & 10 & 5 & 8 & 9 & \\
\hline & & Percent \% & 31.3 & 15.6 & 25.0 & 28.1 & \\
\hline & \multirow{2}{*}{ Total } & Number & 88 & 53 & 45 & 65 & \\
\hline & & Percent \% & 35.1 & 21.1 & 17.9 & 25.9 & \\
\hline \multirow{10}{*}{$\begin{array}{l}\text { Smartphone control } \\
\text { frequency }\end{array}$} & \multirow{4}{*}{$\begin{array}{l}\text { Less than } 10 \\
\text { times a day } \\
11-20 \text { times a } \\
\text { day }\end{array}$} & Number & 23 & 15 & 6 & 15 & \multirow{10}{*}{0.529} \\
\hline & & Percent \% & 39.0 & 25.4 & 10.2 & 25.4 & \\
\hline & & Number & 22 & 14 & 7 & 16 & \\
\hline & & Percent \% & 37.3 & 23.7 & 11.9 & 27.1 & \\
\hline & 21-50 times a & Number & 24 & 14 & 18 & 20 & \\
\hline & & Percent \% & 31.6 & 18.4 & 23.7 & 26.3 & \\
\hline & \multirow{2}{*}{$\begin{array}{l}\text { More than } 51 \\
\text { times a day }\end{array}$} & Number & 19 & 10 & 14 & 14 & \\
\hline & & Percent \% & 33.3 & 17.5 & 24.6 & 24.6 & \\
\hline & \multirow{2}{*}{ Total } & Number & 88 & 53 & 45 & 65 & \\
\hline & & Percent \% & 35.1 & 21.1 & 17.9 & 25.9 & \\
\hline \multirow{10}{*}{$\begin{array}{l}\text { Time after waking up } \\
\text { to smartphone use }\end{array}$} & \multirow{2}{*}{ In 5 minutes } & Number & 33 & 18 & 22 & 34 & \multirow{10}{*}{0.171} \\
\hline & & Percent \% & 30.8 & 16.8 & 20.6 & 31.8 & \\
\hline & \multirow{4}{*}{$\begin{array}{l}\text { In 6-30 } \\
\text { minutes } \\
\text { In 31-60 } \\
\text { minutes }\end{array}$} & Number & 28 & 22 & 15 & 18 & \\
\hline & & Percent \% & 33.7 & 26.5 & 18.1 & 21.7 & \\
\hline & & Number & 15 & 4 & 6 & 9 & \\
\hline & & Percent \% & 44.1 & 11.8 & 17.6 & 26.5 & \\
\hline & \multirow{2}{*}{$\begin{array}{l}\text { After } 60 \\
\text { minutes }\end{array}$} & Number & 12 & 9 & 2 & 4 & \\
\hline & & Percent \% & 44.4 & 33.3 & 7.4 & 14.8 & \\
\hline & \multirow{2}{*}{ Total } & Number & 88 & 53 & 45 & 65 & \\
\hline & & Percent \% & 35.1 & 21.1 & 17.9 & 25.9 & \\
\hline
\end{tabular}

Table 3. Relationships between neck pain and low back pain, smartphone use and physical activity level

Short Form of Smartphone Addiction Scale total $\quad r$ score

Daily Phone Usage Time

Daily Phone Check Frequency

First check-up time after waking up

Vigorous Physical Activity (minutes/week)

Moderate Physical Activity (minutes/week)

Walking (minutes/week)

Sitting time (hours)

** Correlation is significant at the 0.01 level (2-tailed)
Covid-19. The strong association between excessive phone response to environmental stressors to alleviate negative emotion (8). 
In parallel with the increase in smartphone usage, musculoskeletal problems associated with intense smartphone usage are also increasing (10). Studies indicate that with the increase in smartphone use, potential risks for musculoskeletal problems occur $(31,32)$. Neck flexion is the most commonly adopted posture by smartphone users while viewing the screen for a long time, and it can cause many neck disorders (10). In order to read the screen during smartphone use, it is necessary to look down sharply and keep the arms in front, which causes the head to move forward and an excessive anterior curve in the lower cervical spine and an excessive posterior curve in the upper thoracic region to maintain balance, which causes the stress on the cervical spine and neck muscles $(31,33)$. The forward head posture is one of the commonly recognized poor postures in the sagittal plane. It has been reported in the literature that this posture may contribute to the onset and continuation of neck and back pain syndromes and to further loss of cervical spine extension $(34,35)$. Incorrect head and neck posture has been associated with chronic musculoskeletal pain $(36,37)$. Similar to our study, a study in the literature comparing smartphone use and neck problems using a survey showed that smartphone use was associated with neck problems in healthy young adults (38). In another study, it was found that smartphone use in young people caused cervical disc degeneration and chronic neck pain, and excessive smartphone use was identified as a risk factor for cervical problems (39). As a result of our study, it was observed that there was a relationship between some parameters of smartphone usage characteristics and neck problems. As the time spent using the phone increases, the risk of experiencing neck problems increases.

It is reported in the literature that physical activity is a positive factor in the prevention of musculoskeletal diseases. Studies have similarly revealed a significant relationship between physical activity level and neck pain which means higher intensity of physical activity has been associated with a reduced rate of neck pain (38). Although the physical activity levels of the individuals participating in our study were mostly not sufficient, it was found that there was no relationship between neck pain and physical activity level. This may be considered a circumstance related to our study population. The fact that the individuals participating in the study consisted of mostly young people may be the reason for less musculoskeletal pain or it may not have enough time passed over the pandemic that the reduced physical activity level will adversely affect the neck region.

Every individual can experience problems related to the musculoskeletal system in a period of his/her life. It is stated in the literature that spine problems are most common in the low back region (40). It is stated in the literature that poor posture (41), lack of physical activity and depression play a role in back problems $(42,43)$. It is thought that with the restrictions during the Covid-19 pandemic period, the affected physical activity levels of individuals and the rose in stress and anxiety and the increased tendency to depression will cause the increase of back problems in this period (44). In a study examining the prevalence of low back pain in the Covid-19 pandemic period, it was found that back problems increased during quarantine compared to the pre-quarantine period, based on previous prevalence studies in the literature. The results were interpreted as an increase in prevalence due to the negative effects of the restriction measures taken for the Covid-19 pandemic, such as decreasing physical activity participation, increasing sitting time and increasing stress levels (44). Lumbar muscle activation is eliminated with prolonged sitting periods. This results in a decrease in the condition of the lumbar muscles and causes an overload of the passive structures of the body, such as the intervertebral disc and ligaments (45). Although we think that lumbar problems will be seen more commonly as the use of smartphones during the Covid-19 pandemic process reduces the level of physical activity and prolongs their sitting times, there was no relationship between physical activity level, smartphone usage characteristics, and low back pain of individuals who participated in our study. These results may be related to the fact that the assessment was made in the early period of the pandemic. The changes that the pandemic has brought to our lives may not yet have passed enough time to result in the formation of back problems by reflecting on the musculoskeletal system.

If we had the chance to compare the pre-pandemic and post-pandemic physical activity levels, smartphone usage characteristics, low back and neck problems of the individuals participating in the study, then we could more clearly reveal the effects of the pandemic on these parameters. This may be the limitation of our study. In addition, the physical activity levels and smartphone usage characteristics of the individuals participating in our study were determined through surveys. Using objective evaluation methods in further studies may help achieve more reliable results.

As a result of the study, it was observed that physical activity levels were insufficient in the majority of the individuals who participated in the survey. The relationships we expected between physical activity level, smartphone usage characteristics and low back and neck health could not be demonstrated, only weak relationships were found between some features of smartphone usage and neck health. Our study started to be implemented shortly after the Covid-19 cases began to appear in our country. For this reason, the results due to physical inactivity and smartphone usage habits may not yet be at a level that will affect the musculoskeletal system. We think that the evaluation results to be made will be different with the increase in the restrictions and the time elapsed over the duration of cases. We believe that finding solutions to increase the physical activity levels of individuals during the pandemic period will have both protective effects on health and will prevent problems by positively affecting the health of the musculoskeletal system. In addition, we 


\section{Suner Keklik and Numanoglu Akbas / J Exp Clin Med}

consider that creating leisure activities that will increase physical activity levels will change habits related to the use of smartphones and reduce the duration of usage.

\section{Conflict of interest}

The authors report no conflict of interest. There is no declarations of interest. This research did not receive any specific grant from funding agencies in the public, commercial, or not-for-profit sectors.

\section{Acknowledgments}

The study initiated upon the permission of the Ethics Committee of the non-invasive Clinical Trials of Sivas Cumhuriyet University (Decision number: 2020-07/07, Date: 08.07.2020).

\section{References}

1. Brooks SK, Webster RK, Smith LE, Woodland L, Wessely S, Greenberg N, et al. The psychological impact of quarantine and how to reduce it: rapid review of the evidence. Lancet. 2020;395: 912-920.

2. Martinez-Ferran M, de la Guía-Galipienso F, Sanchis-Gomar F, Pareja-Galeano H. Metabolic impacts of confinement during the Covid-19 pandemic due to modified diet and physical activity habits. Nutrients. 2020; 12:1549.

3. Carter SJ, Baranauskas MN, Fly AD. Considerations for Obesity, Vitamin D, and Physical Activity Amid the COVID-19 Pandemic. Obesity. 2020; 28: 1176-1177.

4. Hardman AE. Physical activity and cancer risk. Proc Nutr Soc. 2001;60: 107-113.

5. Astrup A. Healthy lifestyles in Europe: prevention of obesity and type II diabetes by diet and physical activity. Public Health Nutr. 2001;4: 499-515.

6. Ströhle A. Physical activity, exercise, depression and anxiety disorders. J Neural Transm (Vienna). 2009;116: 777-784.

7. Brill PA, Macera CA, Davis DR, Blanir SN, Gordon N. Muscular strength and physical function. Med Sci Sports Exerc. 2000;32: 412-416.

8. Elhai JD, Yang H, McKay D, Asmundson GJG. COVID-19 anxiety symptoms associated with problematic smartphone use severity in Chinese adults. J Affect Disord. 2020;274: 576-582.

9. Briggs AM, Bragge $\mathrm{P}$, Smith AJ, Govil D, Straker LM. Prevalence and associated factors for thoracic spine pain in the adult working population: a literature review. J Occup Health. 2009;1-41.

10. Namwongsa S, Puntumetakul R, Neubert MS, Boucaut R. Factors associated with neck disorders among university student smartphone users. Work. 2018;61: 367-378.

11. Guthold R, Stevens GA, Riley LM, Bull FC. Worldwide trends in insufficient physical activity from 2001 to 2016: a pooled analysis of 358 population-based surveys with 1 . 9 million participants. Lancet. 2018;6: 1077-1086.

12. Kohl HW, Craig CL, Lambert EV, Inoue S, Alkandari JR, Leetongin $\mathrm{G}$, et al. The pandemic of physical inactivity: global action for public health. Lancet. 2012;380: 294-305.

13. Hall G, Laddu DR, Phillips SA, Lavie CJ, Arena R. A tale of two pandemics: How will COVID-19 and global trends in physical inactivity and sedentary behavior affect one another? Prog Cardiovasc Dis. 2020;64: 108-110.

14. Noyan CO, Enez Darçın A, Nurmedov S, Yılmaz O, Dilbaz N.
Akıllı Telefon Bağımlılığ Ölçeğinin Kısa Formunun üniversite öğrencilerinde Türkçe geçerlilik ve güvenilirlik çalışması. Anatolian Journal of Psychiatry/Anadolu Psikiyatri Dergisi. $2015 ; 16: 73-81$.

15. Kwon M, Kim D-J, Cho H, Ynag S. The smartphone addiction scale: development and validation of a short version for adolescents. PloS one. 2013; 8:83558.

16. Kwon M, Lee JY, Won WY, Park JW, Min JA, Hahn C, et al. Development and validation of a smartphone addiction scale (SAS). PloS One. 2013; 8:56936.

17. Saglam M, Arikan H, Savci S, Inal-Ince D, Bosnak-Guclu M, Karabulut $\mathrm{E}$, et al. International physical activity questionnaire: reliability and validity of the Turkish version. Percept Mot Skills. 2010; 111:278-284.

18. Craig CL, Marshall AL, Sjorstrom M, Bauman AE, Booth ML, Ainsworth BE, et al. International physical activity questionnaire: 12-country reliability and validity. Med Sci Sports Exerc. 2003;35: 1381-1395.

19. Fritz JM, Irrgang JJ. A comparison of a modified Oswestry low back pain disability questionnaire and the Quebec back pain disability scale. Phys Ther. 2001;81: 776-788.

20. Yakut E, Düger T, Öksüz Ç Yörükan S, Üreten K, Turan D, Validation of the Turkish version of the Oswestry Disability Index for patients with low back pain. Spine. 2004;29: 581-585.

21. Bolton JE, Humphreys BK. The Bournemouth Questionnaire: a short-form comprehensive outcome measure. II. Psychometric properties in neck pain patients. J Manipulative Physiol Ther. 2002;25: 141-148.

22. Hallal PC, Andersen LB, Bull FC, Guthold R, Haskell W, Ekelund $U$, et al. Global physical activity levels: surveillance progress, pitfalls, and prospects. Lancet. 2012;380: 247-257.

23. Hoffmann B, Kobel S, Wartha O, Kettner S, dreyhaupt J, Steinacker JM. High sedentary time in children is not only due to screen media use: a cross-sectional study. BMC Pediatr. 2019;19: 154-163.

24. Pareja-Galeano H, Sanchis-Gomar F, Santos-Lozano A, FiuzaLuces C, Garatachea N, Ruiz-Casado A, et al. Regular physical activity: a little is good, but is it good enough? Am J Clin Nutr. 2015;101: 1099-1101.

25. Martinez-Gomez D, Lavie CJ, Hamer M, Cabanas-Sanchez V, Garcia-Esquinas E, Pareja-Galeano $\mathrm{H}$, et al. Physical activity without weight loss reduces the development of cardiovascular disease risk factors-a prospective cohort study of more than one hundred thousand adults. Prog Cardiovase Dis.2019;62: 522-530.

26. Pareja-Galeano H, Garatachea N, Lucia A. Exercise as a polypill for chronic diseases. Prog Mol Biol Transl Sci. 2015; 135: 497526.

27. Booth FW, Roberts CK, Laye MJ. Lack of exercise is a major cause of chronic diseases. Compr Physiol. 2011; 2: 1143-1211.

28. Li Q, Guan X, Wu P, Wang X, Zhou L, Tong Y, et al. Early transmission dynamics in Wuhan, China, of novel coronavirusinfected pneumonia. Engl J Med. 2020; 382:1199-1207.

29. Gao J, Zheng P, Jia Y, Chen H, Mao Y, Chen S, et al. Mental health problems and social media exposure during COVID-19 outbreak. PloS One. 2020;15: 1-10.

30. Wang C, Pan R, Wan X, Tan Y, Xu L, Ho CS, et al. Immediate psychological responses and associated factors during the initial stage of the 2019 coronavirus disease (COVID-19) epidemic among the general population in China. Int. J. Environ. Res. Public Health. 2020;17: 1729. 


\section{Suner Keklik and Numanoglu Akbas / J Exp Clin Med}

31. Kang JH, Park RY, Lee SJ, Kim JY, Yoon SR, Jung KI. The effect of the forward head posture on postural balance in long time computer-based worker. Ann Rehabil Med. 2012;36: 98104.

32. Kwon M, Lee JY, Won WY, Park JW, Min JA, Hahn C, et al. Development and validation of a smartphone addiction scale (SAS). PloS One. 2013;8: e56936.

33. Berolo S, Wells RP, Amick BC. Musculoskeletal symptoms among mobile hand-held device users and their relationship to device use: a preliminary study in a Canadian university population. Appl Ergon. 2011;42: 371-378.

34. Burgess-Limerick R, Plooy A, Ankrum DJ. The effect of imposed and self-selected computer monitor height on posture and gaze angle. Clin Biomech. 1998;13: 584-592.

35. McEvoy MP, Grimmer K. Reliability of upright posture measurements in primary school children. BMC Musculoskelet Disord. 2005;6: 35-45.

36. Lau KT, Cheung KY, Chan MH, Chan MH, Lo KY, Chiu TTW. Relationships between sagittal postures of thoracic and cervical spine, presence of neck pain, neck pain severity and disability. Man Ther. 2010;15: 457-462.

37. Szeto GP, Straker L, Raine SJ. A field comparison of neck and shoulder postures in symptomatic and asymptomatic office workers. Appl Ergon. 2002;33: 75-84.

38. Derakhshanrad N, Yekaninejad MS, Mehrdad R, Saberi H. Neck pain associated with smartphone overuse: cross-sectional report of a cohort study among office workers. Eur Spine J.
2021,30:461-467.

39. Zhuang L, Wang L, Xu D, Wnag Z, Liang R. Association between excessive smartphone use and cervical disc degeneration in young patients suffering from chronic neck pain. J Orthop Sci. 2020;26: 110-115.

40. Tunçay S, Yeldan İ. Kas İskelet Sistemi Rahatsızlıklarıyla Fiziksel İnaktivite İlişkili midir? Ağrı. 2013;25: 147-155.

41. Crow WT, Willis DR. Estimating cost of care for patients with acute low back pain: a retrospective review of patient records. $\mathrm{J}$ Am Osteopath Assoc. 2009;109: 229-233.

42. Brady SR, Hussain SM, Brown WJ, Heritier S, Billah B, Wang Y, et al. Relationships between Weight, Physical Activity and Back Pain in Young Adult Women. Medicine (Baltimore). 2016;95: e3368

43. Bento TPF, dos Santos Genebra CV, Maciel NM, Cornelio GP, Simeão SFAP, Vitta A. Low back pain and some associated factors: is there any difference between genders? Braz J Phys Ther. 2020;24: 79-87.

44. Šagát $P$, Bartík P, Prieto González P, Ioan Tohanean D, Knjaz D. Impact of COVID-19 Quarantine on Low Back Pain Intensity, Prevalence, and Associated Risk Factors among Adult Citizens Residing in Riyadh (Saudi Arabia): A Cross-Sectional Study. Int J Environ Res Public Health. 2020;17: 7302.

45. Mörl F, Bradl IJJoe, kinesiology. Lumbar posture and muscular activity while sitting during office work. J Electromyogr Kinesiol. 2013;23: 362-368. 